\title{
Delusional Beliefs in the Clinical Context
}

\author{
Rachel Upthegrove and S. A.
}

\begin{abstract}
Delusional beliefs are key symptoms of mental illness, and physicians over hundreds of years have attempted to understand and offer treatments for patients with such beliefs. In this chapter, the authors will explore the experience of delusional beliefs within the clinical context: i.e. with people who present to mental health services for help. The authors begin with definition of the descriptive psychopathology, prevalence and context in which delusional beliefs occur and their clinical relevance. Delusional beliefs have a core role in distress, depression and risk within
\end{abstract}

Rachel Upthegrove would like to acknowledge the support, enthusiasm and dedication of staff, patients and carers from the Birmingham Early Intervention Service.

S.A. is a Trainee Clinical Psychologist with lived experience of psychosis. The "Healing Healer"? A Psychologist's Personal Narrative of Psychosis and Early Intervention is published in Schizophrenia Bulletin, sbxl88, https://doi. org/10.1093/schbul/sbx188.

R. Upthegrove $(\bowtie)$

Institute for Mental Health, University of Birmingham, Birmingham, UK

Birmingham Early Intervention Service, Birmingham, UK

e-mail: R.Upthegrove@bham.ac.uk

S. A.

Institute for Mental Health, University of Birmingham, Birmingham, UK

(C) The Author(s) 2018

L. Bortolotti (ed.), Delusions in Context, https://doi.org/10.1007/978-3-319-97202-2_1 
psychosis. Real examples will be used to reflect on both the form delusional beliefs take and their personal content, concluding with treatment options and challenges.

Keywords Delusions • Descriptive psychopathology • Distress • Phenomenology $\bullet$ Treatment options $\bullet$ Suicide

\subsection{Why Are Psychiatrists Concerned With THE 'TREatment' of Beliefs?}

Patients, or at times family members advocating on someone's behalf, present to health services in distress and seeking help. In a direct first person account, S.A. explains her experiences of delusional beliefs with candour:

It is said that even Mother Teresa doubted her faith, yet her religious beliefs directly influenced her charitable actions. Unlike Mother Teresa, my delusions had no room for doubt. I was convinced there was a "Challenge" which placed me at the centre of an elaborate scheme to test my suitability for university. "The Challenge" consumed my every being. As part of it I believed people were recording every thought and every word I spoke. I believed that food and drink were poisonous, which led me to not eating or drinking for four days. Unlike Mother Teresa, there was no good in my belief systems: only terror, anguish and exhaustion.

I was relieved that medication reduced the intensity of my experiences over time. My delusional beliefs eventually subsided, after which I felt an incredible sense of loss that things I concretely experienced were in fact my mind's creation.

I never want to face the horror of a delusion state again, and fortunately I have received mostly excellent care from psychiatric services. Without treatment, I wouldn't have been able to go back to leading a "normal" life and certainly wouldn't be training as a Clinical Psychologist. My personal and clinical experience makes me believe delusions are distinct from other, more helpful beliefs, and it is inhumane not to offer people evidence-based treatments for them.

S.A.'s direct account captures the immediacy of delusional experience with eloquence and candour, and conveys the clinical need for intervention to alleviate distress, but also the need for action in the face of real physical impact: S.A. had withheld food and fluid for a number of days. 
This is not a sustainable situation and medicine has this need for action in response to pain and suffering at its core. In the absence of risk or help seeking, psychiatrists and other doctors are not 'thought police' and could not enforce contact or treatment. This is not to deny the abuse of medicine, and psychiatry as a branch of medicine, in darker periods of history; in Soviet countries in the 20th century amongst other examples. Medicine and psychiatry sit within, and are part of, society. It is our social structure and cultural framework that gives context to what defines what are bizarre versus acceptable beliefs. It is thus very evident that we should never lose help-seeking and alleviation of distress or risk as the cornerstone for a psychiatrist's role in treating delusions.

\subsection{Prevalence of Delusional Beliefs}

Delusions rarely occur in isolation. The lifetime prevalence of delusional disorder, defined as the presence of delusional beliefs but no other symptoms of psychosis, is around $0.18 \%$, in comparison to $3.78 \%$ for all other psychotic disorders (Perälä et al., 2007). This is relevant when discussing the context in which beliefs seen in a clinical setting develop, and are held. Delusions are a core feature of schizophrenia, occurring in around $70 \%$, most commonly with concomitant hallucinations and grouped as "positive symptoms" (Fenton, McGlashan, Victor, \& Blyler, 1997). In bipolar disorder, there is less literature charting the occurrence of delusions; similar to the presence of mood symptoms in 'non-affective psychoses' such as schizophrenia, the presence of psychosis in affective disorders at a symptom specific level has not been the major focus of attention. However, our previous work demonstrated that up to $70 \%$ of people with bipolar disorder would experience psychotic symptoms (lifetime prevalence) with $65 \%$ having delusional beliefs (Upthegrove, Chard, et al., 2015). This occurs mostly within an elevated mood (mania) with mood congruent delusions. In major depressive disorder, delusional beliefs are seen in around $20 \%$, mainly the context of severe psychotic depression. Kelleher et al. have also recently demonstrated psychotic symptoms occurring through the range of 'non-psychotic' disorders, regardless of severity, and in the general population (Kelleher \& Cannon, 2011). In DSM-5, "Obsessive-Compulsive and Related Disorders" includes a specific reference to 'delusional insight': whereby the obsessional thought is no longer recognised as erroneous, but held with conviction (APA, 2013). In DSM-V delusional disorder itself now has an exclusion criterion, that symptoms cannot be better 
explained by obsessive-compulsive disorder or similar disorder presenting with a lack of insight. In young people first presenting with mental health problems, in the first development of mental health disorders, diagnostic uncertainty is prominent. In first episode services, delusions are seen in $70 \%$ of patients across affective and non-affective psychosis (Upthegrove et al., 2010). Thus, in classification terms delusional beliefs are now not seen wholly or exclusively indicative of psychosis, and this is novel. Whilst hallucinations have long been recognised to occur in non-psychotic disorders, including epilepsy, personality disorder and post traumatic stress disorder (Pierre, 2010), delusional beliefs were not; as Jaspers wrote "to be mad is to be deluded" (Jaspers, 1997).

Within psychosis delusions usually are seen as one of many symptoms, including hallucinations, disordered thinking, cognitive challenges and changes in mood. In phenomenological terms, when considering a belief or experience and the need to describe it, in and of its own appearance, this is within the content of our own and another's inward concerns: we aim to understand and work with people (Broome, 2013). In psychosis, other positive and affective symptoms will impact the way delusions develop, are conveyed and their personal impact. Bebbington and Freeman recently argue for a transdiagnostic extension of delusions to be explored as an experience in bipolar disorder and delusional disorders as well as in schizophrenia: arguing that symptoms (such as mood disorder and delusions) covary because of a causal interaction between symptoms (Bebbington \& Freeman, 2017). This proposal in entirely in keeping with the premise of this chapter; where we aim to lay out an understanding of the clinical importance of delusional beliefs within the context in which they develop.

\subsection{Phenomenology of Delusions}

Delusions are commonly defined as fixed, false beliefs held with certainty and not in keeping with usual social and cultural context. Delusions have been described as a perverted view on reality, held with unusual conviction, not amenable to logic and with their absurdity or erroneous content easily manifest to others (Oyebode, 2014).

S.A. writes:

I believed there were microphones ("bugs") in my ears that I could switch on and off. This belief was not even shaken when a doctor looked in my ears and confirmed (surprise, surprise) that there weren't any bugs in there. 
Historically, diagnostic weight is given in the distinction between primary delusions, which arise in the absence of other symptoms (a rare occurrence), and secondary delusions, which are secondary to other psychopathology e.g. hallucinations or mood disorder, and are thus understandable in circumstances presented to the individual. For example, a person with mania believing they are a prophet, alternatively with severe depression believing they are guilty for all the evil in the world. The importance is not theoretical, but guides the emphasis of treatment: i.e. focus on the primary cause, in these examples the focus of treatment would be on the mania or depression. In schizophrenia, delusions may be secondary to a range of other positive symptoms (hallucinations, disorganisation) or occur in their primary form:

Andrew walks in to the clinic, clutching a carrier bag, beaming. Despite his many personal challenges, depression has never been a feature of Andrew's presentation. Today however, he is positively upbeat and clearly desperate to show me what is in the bag. 'I've got it doc, I've got proof? Once you see this you will know I am a psychic'. Andrew produces a slightly dog-eared certificate, issued by one of the growing 24 -hour psychic TV channels, certifying that he is a Medium. Andrew has paid $£ 1000$ for this, and with further investment he tells me he will be allowed to receive live calls from the public for telepathic readings. Andrew believes that his talents have brought him to the attention of MI5 and the CIA, who are working together to put him through psychic training by 'telepathically torturing' him until an undefined point in the future, when he will have passed their initiation, and become a member of an elite telepathic spy ring. His feels this job on TV will keep him busy until this day, and his destiny is revealed. His beliefs have been firm for nearly 5 years. The torture he experiences takes place by way of the secret services moving various organs in his body, with a considerable amount of perceived pain, and by them inducing sensations in his rectum and bowels of being raped, together with many voices and tactile hallucinations of being punched, touched and at times even tickled.

Like the back pay from his disability benefits payment, Andrew uses his latest piece of evidence to reinforce his beliefs and with a kind, benevolent disposition takes the clinical teams continued non-committed response as a further sign that the conspiracy is indeed well hidden. We are mere pawns in the bigger game.

Andrew believes he is telepathic and this belief is false, and fixed. It could be debated as to whether it is out of keeping with his social and cultural background, as a belief in telepathy will be shared by a number of 
individuals in modern society. However, Andrew's belief arises secondary to his array of tactile, somatic and auditory hallucinations. He uses extensive and increasing information to reinforce his firm belief and discounts evidence that challenges his conviction.

None of the premises for defining delusions are set in stone (that they are fixed and false beliefs) and each point is are open to challenge. However, the presence, clinical relevance and reality of delusions are not belied by the difficulty in definition. Outside of mental illness, beliefs in God, aliens, political ideologies etc. can be equally fixed, if not more so, on less evidence than Andrew may acquire. Insight may come and go, and with this the fixed nature of delusions. Delusions may not be necessarily false, and occur within a cultural and social context for every individual. Yet despite the readily apparent difficulty in definition, delusions remain a cornerstone of the diagnosis of psychosis and severe mental illness. In asking why psychiatry is so pre-occupied with these erroneous beliefs, it is always important to consider the context within which they arise (i.e. rarely in isolation), but primarily the distress and negative impact they can bring.

\subsection{From Jaspers to the Modern Era}

Karl Jaspers wrote his General Psychopathology in 1913, based on years of detailed clinical assessments of patients with (pharmacologically) untreated mental illness. In describing delusions, Jaspers lays out a two-step process; delusional atmosphere and the crystallisation of this into delusions proper (Jaspers, 1997). Jaspers and then Hagen developed the idea of delusional atmosphere to delusional mood; both authors describing a period of uncertainty, of being aware something is changed:

'Patients feel uncanny, and as though something suspicious is afoot. Everything gets a new meaning. The environment is somehow different not to a gross degree...' The experience of delusional atmosphere or mood is uncomfortable, and the 'full strength of intelligent personality' is called in to understand the experience. Thus, the delusion proper which follows is to some extent a reasoning or resolution of this change (Jaspers, 1997; Stanghellini \& Fuchs, 2013).

S.A. writes:

At an earlier stage of my illness it felt as though the atmosphere of the earth had changed in some way that was difficult to put my finger on. I believe my 
later delusions about being analysed and controlled by others arose from this feeling of something being different, and was a way of my brain trying to explain it.

Maj highlights that Jaspers' account of delusional atmosphere was in itself an unpleasant experience, often accompanied by mood symptoms, ' $a$ distrustful, uncanny tension invades... they suffer terribly... no dread is worse than the dread unknown' (Maj, 2013). The resolution of this uncomfortable atmosphere, delusional belief formation, was seen as a resolution of tension, conflict in thought and experience.

Over a century after Jaspers, the idea of delusional mood has reemerged, with Kapur's model of aberrant salience, further developed by Mishara and Fusar-Poli (Kapur, 2003; Mishara \& Fusar-Poli, 2013). The primary difficulty they propose lies in dopamine firing independent of cue. In usual semantic memory development and retrieval, sub-second awareness of the significance of an environmental stimulus is needed, all the time. However, we lack the time and ability to constantly consciously ascertain the significant signal; e.g. food, to assess the shape, colour, smell etc. Seen once, a tiger will remain threatening in our memory and one will always remember the smell, texture and taste of chocolate. These semantic memories are hard wired, quickly, through a salience dopamine pathway.

There is increasing evidence that in psychosis, increase release and unconnected triggering of dopamine occurs (Murray et al., 2008). This is a much more nuanced understanding than an excess of dopamine leading to psychosis. Dopamine is a key neurochemical for memory and memory retrieval, and is increased at a cellular sub-second threshold when one is confronted with important information (the tiger or chocolate). If this firing happens independent of cue, as is proposed, supposedly neutral objects or pieces of information may assume significance; the environment somehow seems different, benign objects acquire special meaning. Inappropriate salience is assigned to external and internal stimuli; thus, a passing car becomes perplexing, or perceived as a threat, memories become pre-occupying or take on new significance.

More recent meta-analysis have confirmed dopamine dysregulation in psychosis; with the summary of findings being increased dopamine synthesis capacity, dopamine release and synaptic concentrations, the sum result of which is increased availability of dopamine to be present 'independent of cue' (Howes et al., 2012). Furthermore, key dopamine and salience networks in the brain have consistently been shown to be 
functioning differently in patients with psychosis. We are now aware that the brain changes in psychosis will not be related to one area or region, or on indeed one chemical, however certain brain networks of neuronal connections are increasingly recognised as important in our higher order thinking.

The Salience Network consists of the anterior cingulate cortex and anterior insula and, in health, is involved when our attention is needed- it will activate when we need to attend. The Default Mode Network, consisting of the posterior cingulate, ventromedial prefrontal cortex, inferior parietal cortex and angular gyrus, is active when we are not attending (e.g. day dreaming) and the Central Executive Network is involved in our decisions around what is important to attend to, and processing and responding to the complex information. Individuals with psychosis have structural, functional and neurochemical changes within these three networks and how they activate; Palaniyappan, Mallikarjun and Liddle propose switching is a key difficulty; with default mode downregulation not occurring when it should, leading to inappropriate significance being placed on previously benign signals and delusional interpretation of external or internal cues (Palaniyappan, Mallikarjun, Joseph, White, \& Liddle, 2011).

Whilst Jaspers was writing about the phenomenology and subjective patient experiences, of distress, delusional mood and the need for resolution, there is a wealth of information now available that builds on this in our understanding of the context in which delusional beliefs are formed; within the context of a change in brain function. In keeping with the tenant of this chapter, however, it should be noted that these changes are not necessarily specific to delusions over and above other positive symptoms; hallucinations may equally be attributable to dopamine activation independent of cue, with that cue being our own inner speech and salience network dysfunction, or the failure to down regulate the default mode network result internal processes being experienced as heard perceptions (Upthegrove, Ives, et al., 2016). The intricate need for understanding hallucinations and delusions together remains prominent. Primary delusions, the springing to mind of fully formed beliefs, complex and fixed, sometimes preceded by a mood of disquiet (delusional mood), are rarely captured. Current understanding and research in delusional beliefs is largely based on persecutory beliefs, as a continuum approach, or secondary delusions. 


\subsection{Psychosis Continuum}

In the past 20 years, the early identification of psychosis has become a priority, based on the knowledge that a longer duration of untreated psychosis is associated with poorer outcomes, functional decline and risk. In the UK and Australia, Early Intervention in Psychosis (EIP) services have been set up with the aim of early identification of young people with first episode psychosis, and also those at risk of developing psychosis. Criteria for 'Ultra High Risk' (UHR) patients, i.e. those at higher risk of developing psychosis, but not yet psychotic, and the concept of an 'At Risk Mental State' (ARMS) includes at the heart a definition of a psychosis as the presence of positive symptoms, including delusions, and that this psychosis exists in a continuum between normal experience and illness (Marwaha, Thompson, Upthegrove, \& Broome, 2016). EIP services often offer support and treatment to individuals who may be at high risk of developing psychosis, before frank illness is present, before positive symptoms including delusions are fully developed. In work by Yung et al. (Yung et al., 2008; Yung et al., 2005), ARMS young people are defined as a helpseeking population with either low grade or frequency psychotic like symptoms, very brief self-resolving periods of delusional like thinking and a family history of psychosis along with functional decline. Low-grade psychotic like symptoms may include unusual thoughts or non-bizarre ideas that are not held with a fixed belief, or if they are, they are brief and limited, resolving without interventions. As a group, their relative risk of developing full psychosis in a 3 -year period is around 500 times that of the general population (Nelson et al., 2013).

There remains the need for valid biological markers of a psychosis continuum and the staged model of psychotic illness, to aid accuracy of prediction of future psychosis and staged interventions. However, Reniers and colleagues recently demonstrated a neurobiological signature for poorer functional outcome in the ARMS group, consisting of reduced grey matter density in bilateral frontal and limbic areas, and left cerebellum, which may be more clinically relevant than transition to a predetermined definition of psychosis (Reniers et al., 2017). Structural brain alterations are clearly present in those who have schizophrenia and related psychoses, including increase in ventricular volume and reduced grey and white matter. It has also been shown that these changes are present before the onset phase of frank psychosis (Smieskova et al., 2010). The majority of UHR individuals do not transition to psychosis but many continue to 
have other poor outcomes and lower functioning (Reniers et al., 2017). However the point here is firstly that it is proposed that delusions may exist on a continuum and that positive symptoms are conceptualized together, frequently co-occurring. Their sum total is more than the individual experience of one in isolation, but may not be the most relevant feature of how one functions in the world.

Cornblatt and colleagues propose a dimension of UHR status that has an underlying vulnerability for positive psychotic symptoms driven to clinical significance by cognitive deficits, mood disturbances, social isolation, and school failure (Cornblatt et al., 2003). An alternative approach to recognizing developing psychosis before frank delusions are present has been proposed within the European tradition of Basic Symptoms. Schultze-Lutter and Ruhrmann developed UHR criteria based on basic symptoms as a complement to attenuated positive symptoms, and this aids predictive validity of psychosis risk (Schultze-Lutter, Ruhrmann, Berning, Maier, \& Klosterkötter, 2008). Basic symptoms are subtle, sub-clinical self-experiences such as disturbances in drive, stress tolerance, attention, thinking, speech, perception and motor action. First described by Huber, they are based in the subjective understanding of difference from a 'normal' self (Huber \& Gross, 1989). Ruhrmann proposes that basic symptoms are compensated for by increasing effort, not available to observation from others, and are recognized by an individual as a product of their own mind (Schultze-Lutter, Klosterkötter, \& Ruhrmann, 2014). With relevance to delusions, cognitive basic symptoms include disturbances in thought processing such as thought blockages, perseveration and pressure. Broome demonstrated individuals at high risk of psychosis were more likely to jump to conclusions (JTC) on the basis of less information when cognitive demands are high (Broome et al., 2007). Subjects at high risk of psychosis and controls completed a bead-jar task, where by decisions on which of two jars with different numbers of coloured beads are made when a varying number of beads are shown. A JTC bias is seen when subjects make a decision about which jar on fewer number of beads. When involved in an additional working memory task, subjects with high levels of delusional like thinking were more likely to show a jumping to conclusions bias. Thus the primary cognitive difficulty or working memory was managed by decision-making at an earlier stage. A subtle compensatory response to basic cognitive disturbance demonstrates that even at the first delusional belief formation stage, the influence of other 'symptoms' or processes are key (Garety \& Freeman, 1999). 


\subsection{Delusions in Context}

As illustrated in Andrew's presentation, delusional beliefs in frank psychosis do not occur in isolation, and the understanding of their experience requires appreciation of the wider context. As illustrated in S.A.'s account, for many people delusional beliefs are terrifying, consuming experiences, directly related to depression or severe anxiety. Delusional belief may arise secondary to, or in conjunction with, other symptoms; believing that you are being followed as the result of a voice telling you this happening, believing there are telepathic cameras in the walls because somehow your thoughts are being broadcast on the radio. These beliefs are understandable, and have logic. In Jaspers' view these would be delusion-like ideas, and not 'true' delusions (Oyebode, 2014). It must be emphasised that the historical context of the phrase 'true delusions' or 'delusions proper' did not negate the significance or distress of Jaspers' concept of delusion-like ideas, but underlied that there was significance in the cognitive process and the treatment implications that primary delusions bring.

\section{Delusions and Hallucinations: Positive Symptoms}

As rehearsed above, the majority of patients will experience both delusional beliefs and hallucinations together as part of 'positive symptoms' of psychosis. Their experiences are interdependent, and can have a combined significant bidirectional impact on an individual's distress, help seeking behaviour and functioning. When investigating the experience of hallucinations in psychosis, this intricate relationship is clear; how one interprets early hallucinatory experiences, attributes cause and meaning to voice content is significant in psychosis. Delusional interpretation of hallucinations is common, particularly in developing illness.

S.A. remarks:

I believe that my delusion that the water supply had been contaminated was as a result of the water itself tasting different (i.e. a gustatory hallucination).

In a phenomenological study investigating the subjective experience of voice hearing in 25 young people with first episode psychosis, first person accounts show that hallucinations were characterized by an experience of entity: as though from a living being with complex social interchange and 
control. Voices were often percived as speaking as an expert authority, able to control individuals, received with passivity and accompanied by sensation in other modalities (Upthegrove, Ives, et al., 2016). Thus, is not surprising that delusional beliefs of communication or possession were a common accompaniment such experiences. Direct quotes from individal experence give illustration below:

'it's like being possessed, you know. What can you do? What can you really do?'

'it's like I'm being held down'

'I'm constantly caged in by voices'

'my body will recognise it'

'When they choose to talk to me, they choose to talk to me and they take over they take over the whole situation as it is at the time'

'it's out of my hands'

'if it's really strong, the pull, I just lose whole control of it'

The experience of voice hearing is often accompanied by a search for meaning, an understanding of what can be an unusual and isolating experience; shame, and self-stigma lead to and isolation and can result in individuals not discussing experiences with a trusted other, and searching for meaning on their own;

'I don't know what kind of game they're playing but someone's gonna end up getting hurt really bad if they keep it up, whether it's me or them' 'there must be a camera in the TV then, I mean I don't give a shit' 'Is there a solution, has someone else gone through this, is there information on what I'm going through?'

'I've experienced it for a good long time on my own because I was embarrassed by it so I did go internet'

'made me think... is this really happening... I mean are these people being watched or something'

'that's probably why they're using voices that you recognise from back in the day and it's like "We use these to try to connect"

Thus in our phenomenological study in first episode psychosis, the experience of auditory hallucinations are much more than a mere auditory phenomenon. In a modern phenomenological investigation, without presupposition, results echo known descriptive psychopathology. Novel findings also emerged that may be features of hallucinations in psychosis not currently captured with standardized measures used to assess voices in research and clinical settings. However the complex, personal and multi- 
sensory nature of hallucinations is readily apparent. Hallucinations were received with passivity, and lead to the need to understand this experience, and for some individuals a delusional explanation.

\section{Delusions and Mood}

Garety and Freeman have long written on the centrality of mood symptoms (depressionand anxiety) in the maintenance of delusional beliefs. Persecutory delusions can be seen as beliefs of threat, and so share the subjectve experience of an anticipation of danger with anxiety disorders. People with persecutory delusions may act in ways, like those with anxiety disorder, to keep safe, and will thus avoid exposure to dis-confirmatory evidence (Freeman, Garety, \& Kuipers, 2001). However we have also shown the common occurrence of depression in developing and early psychosis: and that this may indeed be more than a 'comorbidity' (Upthegrove, Marwaha, \& Birchwood, 2016; Upthegrove, Ross, Brunet, McCollum, \& Jones, 2014). Depression can be seen as a reaction to the threat posed by perceived persecutors, malevolent voices and engagement in safety behaviours leading to feelings of entrapment. Garety and Freeman's work (Freeman et al., 2001; Freeman et al., 2007) demonstrates the significance of safety behaviours in the development and maintenance of delusional belief and distress. This suggests the personal significance and reaction to perceived threat is more individually important than the severity of symptoms as measured by delusional conviction or voice frequency.

Our work has demonstrated that personal appraisal of anomalous experiences may drive on-going emotional dysfunction and through this further increases in the fixed nature of delusional beliefs. Thwarted escape, arrested flight and failure to exert or win control of symptoms through use of self-help or safety behaviours may drive further isolation, lack of exposure to dis-confirmatory evidence and longer duration of untreated illness (Upthegrove, Marwaha, et al., 2016). Learned helplessness, in response to unrelenting positive symptoms also leads to depression until treatment or help finally arrives. This is in keeping with advances in our understanding of anxiety and distress in psychosis whereby proneness to shame is driven by social anxiety disorder (Kesting \& Lincoln, 2013; Rüsch, Angermeyer, \& Corrigan, 2005).

Building on the importance of mood symptoms in the development and maintenance of positive symptoms, it is also proposed that the context of adverse experiences in childhood will lead to the development of negative schemas of the self and the world (the self as vulnerable and others as 
dangerous) which facilitate the development of paranoid delusions (Birchwood et al., 2004; Garety, Kuipers, Fowler, Freeman, \& Bebbington, 2001).

S.A. writes:

The content of my delusions (e.g. being tested to see if I was 'good enough' for university) directly related to what I believed about myself, for instance that I was inferior to other people.

Birchwood and colleagues suggest that childhood experience of social adversity leads to the development of negative schemas involving social humiliation and subordination, which in turn may fuel paranoia (Birchwood et al., 2004). Alternatively, within biological models of schizophrenia the experience of abuse is proposed to create vulnerability to psychosis through heightened stress reactivity and cortisol dysfunction (Cannon, Clarke, \& Cotter, 2014; Catone et al., 2015). Etain and colleagues suggest that a dual role of genetic and environmental influences of socially and morally inappropriate rewards and parental attitudes during childhood induces affective dysregulation in the developing child that precedes the development of bipolar disorder (Etain, Henry, Bellivier, Mathieu, \& Leboyer, 2008).

We have previously investigated delusions in bipolar disorder, using data from 2019 participants from the Bipolar Disorder Research Network, the largest bipolar sample in the world, with lifetime-ever DSM-IV and lifetime-ever clinical characteristics including childhood trauma, presence/absence of specific delusions (including persecutory, grandiose, depressive, nihilistic, guilt, and reference); auditory hallucinations (including mood congruent hallucinations, accusatory/abusive and running commentary) and visual hallucinations (including all visual and mood congruent visual hallucinations). We hypothesised adverse childhood events would show a significant association with positive symptoms driven by dysregulation of mood (mood congruent delusions and hallucinations) or with a persecutory or abusive content. However, our hypothesis was only partially upheld. We demonstrated significant associations between childhood abuse and hallucinations which are mood congruent, or with an abusive content. These types of hallucinations remained significantly associated with childhood sexual abuse even after controlling for other factors such as cannabis misuse. Significant associations were also found for other types of adverse childhood life events, including the experience of bullying 
and hallucinations but there was not an increased risk of delusional beliefs, or in any sub type of delusional beliefs, in those with childhood traumas (Upthegrove, Chard et al., 2015).

In this respect, our results were contrary to studies in schizophrenia, or in those sampling from a population based cohort investigating associations between childhood trauma and persecutory ideation. However, the majority of this research concerning childhood adverse experiences and psychosis tend to show childhood emotional and sexual abuse are most notably associated with auditory hallucinations; Daalman and colleagues found that psychotic patients with auditory verbal hallucinations were 3 times more likely to be victims of childhood sexual abuse and over 5 times more likely to have suffered emotional abuse than healthy controls (Daalman et al., 2012). In fact, relatively few studies have shown a direct relationship between childhood trauma and fully formed delusions in clinical samples specifically. It may well be that the relationship between childhood events and psychosis is more symptom-specific than first proposed or that hallucinations are the mediating step between trauma and delusional beliefs. This will have relevance through the whole psychosis spectrum, however the weight of symptoms may differ across an affective load. An alternative explanation may be that in bipolar disorder, where there is less cognitive impairment compared to core schizophrenia, the role of childhood trauma appears specific in the predisposition to hallucinations. Additional cognition inefficiency maybe needed for the pathway to be directly between trauma and delusional beliefs.

However, it is also possible that mood symptoms are intricately linked to delusional beliefs at the biological level. Regions critical to emotional processing are common in models of psychotic symptoms and include the hippocampus, insula and prefrontal cortex. These areas are implicated in both depression with psychosis and schizophrenia (Busatto, 2013). In broader terms of affective instability, there is some convergence of evidence that alterations in amygdala activation is involved in difficulty in emotional processing, salience to emotional stimuli, and behavioural response (Broome, He, Iftikhar, Eyden, \& Marwaha, 2015). This may not only explain some of the commonality in biological findings across psychotic mood disorders and schizophrenia, but provides potential aetiological pathways.

Recently we have proposed that mood may drive forward further symptom dimensions in psychosis, including delusional beliefs, through a stress-inflammation-structural brain change pathway. Evidence shows that 
first episode schizophrenia and first episode affective psychosis have similar changes in brain structure, although progressive insular grey matter loss may be more pronounced in schizophrenia (Lee et al., 2015). Increase in stress reactivity seen in schizophrenia may be linked to inflammatory and structural brain changes (Lataster, Valmaggia, Lardinois, van Os, \& MyinGermeys, 2013). Hippocampal grey matter volume (GMV) reduction is found in unipolar depression, related to the duration of illness (Arnone et al., 2013) but is also seen in schizophrenia. Inflammation mediated effects on brain derived neurotrophic factor (BDNF) is a proposed pathway for this effect (Mondelli et al., 2011). Changes in circulating inflammatory markers and neurotrophins associated with the onset of depression are also seen commonly in schizophrenia (Upthegrove, ManzanaresTeson, \& Barnes, 2014); psychosis and depression may in combination be significant at a biological inflammatory level; Noto recently demonstrated that IL-6, IL-4, IL-10 and TNF $\alpha$ were significantly higher in this patient group (Noto et al., 2015).

In brain imaging using functional magnetic resonance imaging (fMRI), patients with depression and positive symptoms show similarly enhanced brain response to fearful facial expressions, particularly located to the thalamus (Kumari et al., 2015). Regions critical to emotional processing are common in models of psychotic symptoms and include the hippocampus, insula and prefrontal cortex and these areas are implicated in both depression with psychosis and schizophrenia (Busatto, 2013). There is also convergence of evidence that alterations in amygdala activation is involved in difficulty in emotional processing, salience to emotional stimuli, and behavioral response as related to affective instability (Broome et al., 2015).

\section{Delusions and PTSD}

Around one in three people with psychosis report symptoms consistent with post traumatic stress disorder (PTSD), and this can be related to the experience of positive symptoms themselves. Brunet et al. explored PTSD in relation to symptoms and the experience of psychosis in a community sample of patients with first episode psychosis. 31\% met DSM-IV criteria for PTSD (Brunet, Birchwood, Upthegrove, Michail, \& Ross, 2012), a figure in keeping with PTSD rates after national disasters, and higher than other man-made or technical incidents (Neria, Nandi, \& Galea, 2008). In psychosis, more people still report distressing memories subthreshold for PTSD such that two thirds of people experienced distressing intrusive 
memories at some level (Brunet et al., 2012). PTSD symptoms were often related to psychotic symptoms, which continued to distress participants longitudinally after their first acute episode. In relation to delusional beliefs, threatening persecutors were distressing. Chisholm et al. previously demonstrated the appraisals of threat or harm arising from these experiences and the accompanying distress was associated with PTSD status and severity and those with PTSD appraised their persecutors as more powerful, awful, deserved, and felt less in control or able to cope (Chisholm, Freeman, \& Cooke, 2006).

S.A. writes:

Once I had recovered from my psychotic episode I struggled with distressing memories of what had happened. I didn't develop full PTSD but can understand why it is so common.

\section{Delusions and Suicidal Thinking}

In keeping with the premise the clinical context of this chapter, it is important to rehearse suicidal thinking: a clear consequence of delusional beliefs over and above depression and distress. The intricate relationship between mood and delusions has significant consequence. Suicide in psychotic disorders remains too frequent an event and a tragic, preventable loss of life with widespread impact to family, carers, friends and society. In our previous work in first episode psychosis, over $50 \%$ of individuals with psychosis reported clear thoughts of self-harm. 33\% reported a lifetime history of suicidal behaviour and $30 \%$ had a history of suicidal behaviour in the developing months of first episode psychosis or during a period of untreated positive symptoms. Methods used in this cohort include overdose attempted hanging and jumping from a height (Upthegrove et al., 2010). The presence of depression significantly associated with the presence of acts of selfharm. Our investigation of first episode psychosis identified key variables in prediction of suicidal behaviour including male gender male, minority ethnicity grouping, substance abuse and a history of depression (Upthegrove et al., 2010). As we have previously rehearsed, depression can be experienced as a complex reaction to psychosis, including delusional beliefs and the impact of psychosis, thwarted escape, self stigma and internalised shame contributing to a pathway of suicidal thinking (Fig. 1.1):

We have explored this model with qualitative methods using photoelicitation, together with unstructured interviews, used to characterise 


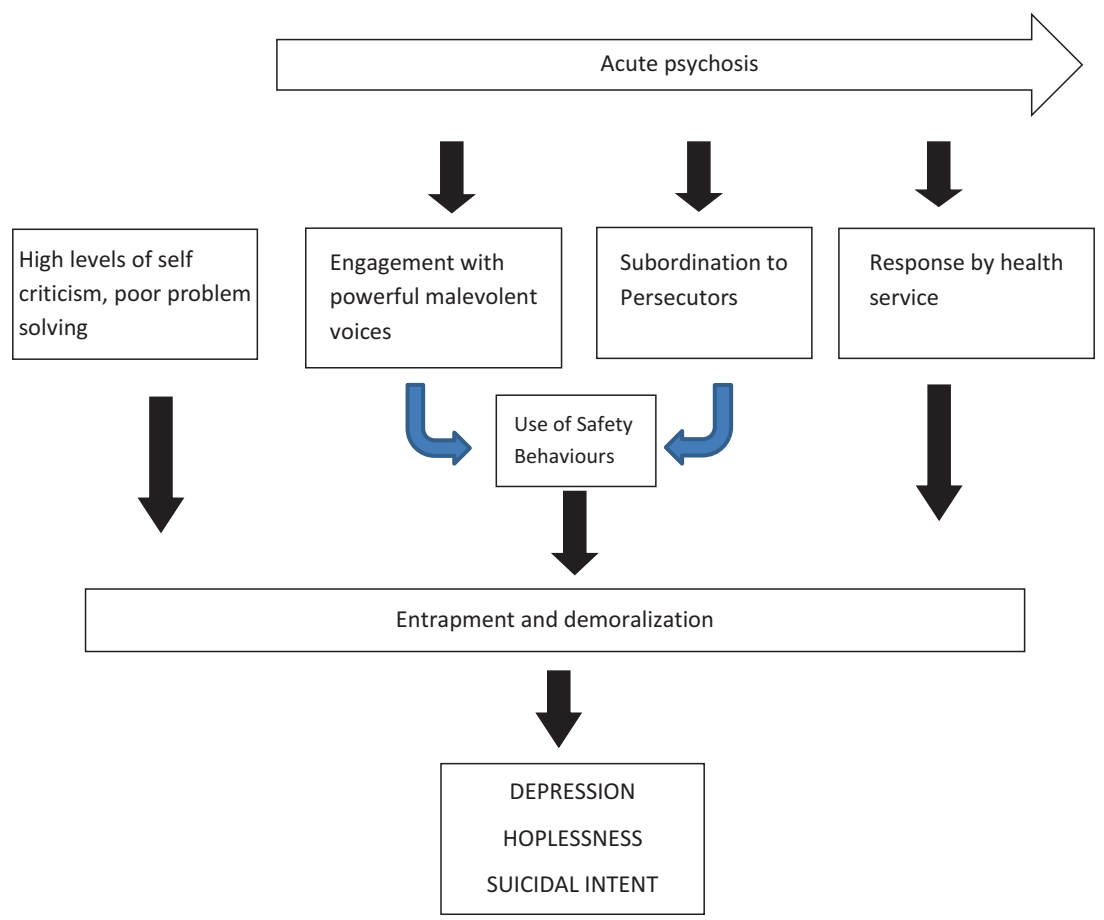

Fig. 1.1 Model of suicidal behaviour in psychosis

aspects of depression following FEP and analysed using contemporary framework analysis. Participants reported a long period of self reflection and an in-depth questioning of their illness events together with a difficulty in trusting their own thoughts and experiences. See Fig. 1.2 and excerpts below from Sandhu et al. (Sandhu, Ives, Birchwood, \& Upthegrove, 2013):

'That's me describing my mind sometimes, it's kind of like confusion ... because after I had a psychosis episode, that's how my mind was like, fully confused, and I couldn't break out of it'.

Some participants extended the doubt of their thoughts and memories, and raised the possibility that they had been delusional for a much longer period than they originally thought. They also experienced confusion 


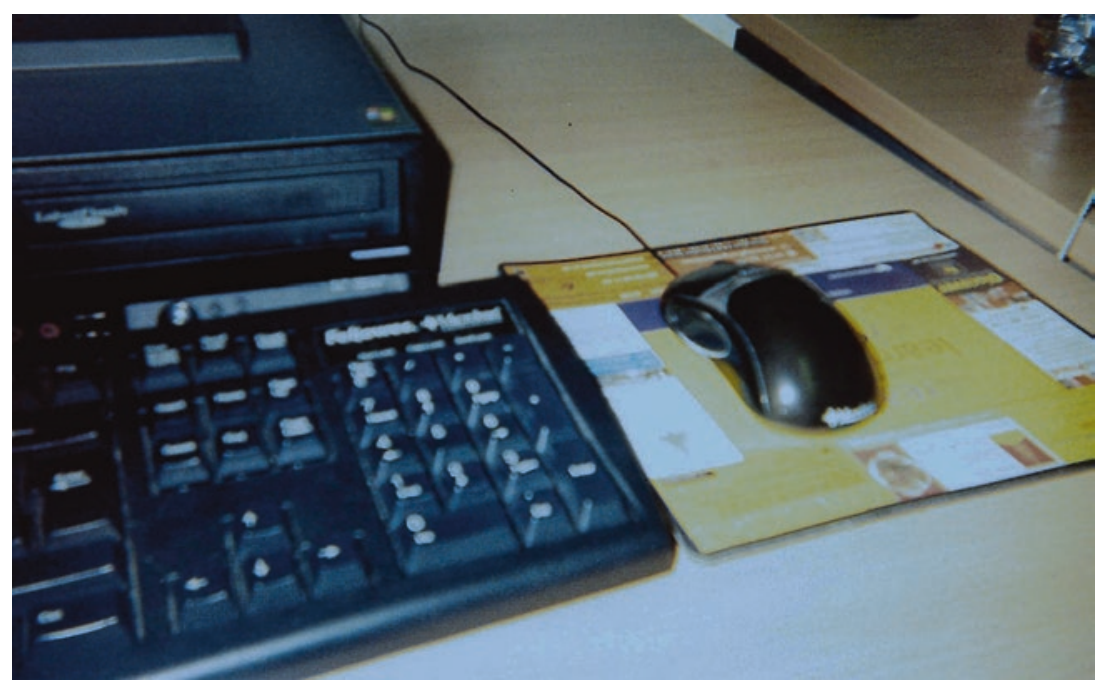

Fig. 1.2 The participant reported with this illustration "for a big part of time I was like looking on the internet... trying to understand what's happened to me... there's the part of this experience of 'what's going on?' leads you to try and investigate”

about the present, and reported an increasing sense of mistrust of both their current thoughts and their current experience of "reality":

'I started to realise, if most of the things that I was scared about, and you know, a lot of my thoughts, were they to do with psychosis? ... It's come to the stage where I don't one hundred percent trust myself.'

'Once you realize that you've lost track of reality and your mind starts getting to grips with the fact that it was wrong, it was completely wrong for so long, I dunno, you kind of lose your confidence in your own judgment'

We also observed an overwhelming sense of shame, which strengthened participants' feelings of loss and social withdrawal. There is substantial evidence that people with mental health disorders, particularly schizophrenia, are heavily subjected to stigma by society and individuals can internalize this stigma and suffer shame, loss of self esteem and isolation (Staring, Van der Gaag, Van den Berge, Duivenvoorden, \& Mulder, 2009). Superimposed onto these experiences, our findings suggested an on-going relationship between these disempowering appraisals 
and fear of psychosis, and the return of delusional thinking adding to loss and isolation. Participants cited feeling safe in isolation, of wanting to be left alone. There was a perceived pressure to 'be better' once positive symptoms had abated; yet with little knowledge about how to begin this, adding to a sense of despair and demoralisation (Sandhu et al., 2013).

Formal comparison between social anxiety disorders and social anxiety in psychosis has recently revealed differing mechanisms involved in maintaining anxiety in patients with psychosis; patients with psychosis experiencing more perceived threat and anticipated harm, without the presence of persecutory delusions. The suggestion is, similar to depression following psychosis, different mechanisms may be involved when affective dysregulation occurs in psychosis (Michail \& Birchwood, 2009).

\subsection{Therapeutic Options}

The first thing to note is that the treatment for delusional beliefs, like their development, does not occur in isolation. Patients present to services with the above rehearsed concomitant distress, hallucinations, depression or suicidal thinking. Therapeutic options are planned with the patient, and their personal formulation, as a whole. On occasion, delusional beliefs singularly come with actions that present significant risk to self or others and this may result in more coercive treatment frameworks, including that involving legislative frameworks. This latter scenario is outside of the scope of this chapter, and would warrant an additional rehearsal of ethical debate and therapeutic challenge. Thus, we will discuss treatment options that mental health professionals; psychiatrists, nurses and psychologists discuss with their help-seeking patient.

That said, risk assessment and management are core features of clinical services. As illustrated above, significant distress, suicidal thinking and actions can accompany delusional beliefs. At times services can struggle with the balance of individual autonomy versus interventions that may save lives, whilst still aiming to offer real clinical hope. The absolute need to engage therapeutically with people in the midst of extraordinary personal experiences are not easily captured or helped by dry definitions of psychopathology, labelling symptoms, establishing diagnostic criteria or an understanding of the underlying neurobiology. In order to offer treatment and interventions, and reduce risk of suicide, there is a need to understand and empathise with an individual's experience - to walk fully in someone else's 
shoes. This takes time and effort. Therapeutic engagement should be the starting point and continuing cornerstone of pharmacological or psychological treatments, which will not be accepted, or be effective, without.

S.A. writes:

Before I saw professionals from the Early Intervention Service I didn't feel listened to or understood. My psychiatrist and CPN took time to listen to me and I felt they placed themselves alongside me rather than in a position of power. If they hadn't taken time to get to know me I wouldn't have felt able to trust them or the advice they gave me.

\section{Medication}

There is substantial and robust evidence that antipsychotic medication is effective in the treatment of positive symptoms of psychosis (i.e. delusions, hallucinations and disorganisation of thought). The British Association for Psychopharmacology (BAP) guidance summarised evidence that the majority of patients with positive symptoms will respond to antipsychotic medication and recommends that the choice of first-line antipsychotic drug should be based on the evidence for relative liability for side effects, individual patient preference, individual patient risk factors for side effects and relevant medical history. Antipsychotic medication should be initiated at the lower end of the licensed dosage range when first commenced and an individual trial of the antipsychotic of choice should be conducted: i.e. it is not advised, nor responsible, to continue prescription for medication which may have side effects but has not shown a therapeutic benefit. Clozapine should be considered for patients whose illness has shown a poor response to trials of two antipsychotic drugs that have been adequate in terms of dosage and duration (Barnes, 2011). With regard to delusional beliefs in particular, the duration of illness (untreated) is related to the effectiveness of pharmacological, and likely psychological, interventions: With many years to entrench belief systems, time to spend gathering evidence and the potential progressive brain changes seen in the early years of psychosis, less response to therapies may occur. Drake and colleagues clearly showed some time ago that the length of untreated psychosis corresponded to the severity of positive symptoms at first presentation and the response to treatment (Drake, Haley, Akhtar, \& Lewis, 2000).

Similarly to BAP guidance, the National Institute for Health and Care Excellence (NICE) recommendations for the treatment of schizophrenia 
and psychosis include the prescription of an antipsychotic medication (in combination with psychological interventions) as the first step in the treatment of psychosis (Kuipers, Yesufu-Udechuku, Taylor, \& Kendall, 2014):

The choice of antipsychotic medication should be made by the service user and healthcare professional together, taking into account the views of the carer if the service user agrees. Provide information and discuss the likely benefits and possible side effects of each drug, including: metabolic (including weight gain and diabetes) extrapyramidal (including akathisia, dyskinesia and dystonia) cardiovascular (including prolonging the QT interval) hormonal (including increasing plasma prolactin) other (including unpleasant subjective experiences).

NICE guidelines are not without controversy, as highlighted by open debate in the British Journal of Psychiatry (Kendall et al., 2016). NICE gives equal or indeed enhanced emphasis on psychological over pharmacological interventions, including cognitive behavioural therapy for psychosis (CBTp) and art therapy, which have a considerably less developed evidence base and thus the guideline has been said to have shown a negative bias to drug treatment. The Scottish Intercollegiate Guideline Network (SIGN) is the Scottish equivalent to NICE. Whist both guidelines have a number of similarities, for example recommending the use of antipsychotics (including clozapine when needed), family intervention, early interventions, assertive community treatment and CBTp, SIGN offer more extensive recommendation on pharmacological treatment, with some $60 \%$ of its recommendations devoted to pharmacological interventions alone(Taylor \& Perera, 2015). The argument of bias of NICE towards psychosocial interventions was felt to be based on a belief that antipsychotic medications are more potentially harmful. There is an absence of evidence for adverse effects of psychosocial interventions; however the argument is that the absence of evidence is not the same as evidence of absence.

In terms of medication choice, as BAP guidance's state, this should be based on individual patient presentation and choice, as there is no clear evidence to suggest one antipsychotic medication is likely to be more effective than another within an individual patient trial with the exception of clozapine. The European First Episode Schizophrenia Trial (EUFEST) tested haloperidol against several 'second generation antipsychotic medications' in first-episode schizophrenia and schizophreniform disorder. All medications showed an effect on positive symptoms with a mean symptomatic improvement of 
more than 60\% (Kahn et al., 2008), thus choice should be made on the balance of side effects, previous history of response and with patient choice.

S.A. writes:

It's very important for clinicians to offer people a choice in the medication they are prescribed, and to be prepared to switch medications if the side effects can't be tolerated. Personally I felt embarrassed about some of my side effects so I think it's important clinicians ask about them directly.

In addition, epidemiological evidence is clear on the effectiveness, and safety, of antipsychotic medication. In a cohort of over 20,000 people in a Swedish database study demonstrated the effectiveness of antipsychotic medication in terms or treatment, prevention of relapse and hospitalization. Clozapine and long acting injections were superior to other forms of medication, likely the result of increase efficacy (clozapine) and concordance monitoring (both) (Tiihonen et al., 2017).

Lally et al. have also recently demonstrated optimistic remission and recovery figures in treated first episode psychosis, with remission in nearly $60 \%$ of people at 5 years remaining well (Lally, J. et al. 2017). Antipsychotic medication is effective in the prevention of relapse and randomized controlled trials strongly support the efficacy of antipsychotics for the acute treatment of psychosis and prevention of relapse (Goff et al., 2017; Leucht et al., 2012) There is also growing opinion that a significant minority of people can remain well on very low dose medication after the treatment of the acute episode (Murray et al., 2016). In contrast, meta-analysis conducted by Vermeulen showed an increased long-term mortality risk in patients with schizophrenia who did not use antipsychotic medication during follow up (Vermeulen et al., 2017). Thus in clinical decision, individual formulation including risks of relapse is needed, with careful consideration of positive effects and side-effects of medication including propensity to cause sedation and weight gain or stiffness, rigidity and tremor, balanced by the prevention of return of delusions and hallucinations, and reduced risk of suicidal behaviour (Barnes, 2011). A focus on the treatment of delusions beliefs themselves should not detract from effective treatments of the impact delusional beliefs may bring. We have recently demonstrated the effectiveness of antidepressants in the treatment of depression in schizophrenia (Gregory, Mallikarjun, \& Upthegrove, 2017) and Helfer has also demonstrated the long term role of antidepressants in suicide prevention in psychotic disorders and their safe use in combination with antipsychotic medication (Helfer et al., 2016). 


\section{Psychological Therapy}

Cognitive therapy is a predominent psychological treatment is used in the majority of mental health disorders with differing levels of proven efficacy. Fairly robust evidence exists for Cognitive Behavioural Therapy (CBT) in depression and anxiety (Clark, 2011). Historically, the concept of psychological therapy for delusional beliefs was not encouraged: concern that targeting delusions directly was likely to make matters worse, within an understanding that delusions were not amenable to reason nor subject to 'normal' mechanisms of learning, and therefore talking through the evidence was counterproductive. In fact this position was unrelated to Jaspers first accounts of delusional beliefs and logical reasoning, which did not equate to a therapeutic nihilism, yet did lead to a lack of focus of psychological therapies for psychosis for some decades.

However Cognitive Behaviour Therapy for psychosis (CBTp) now has an evidence base, although the strength of this base is debated. The effectiveness of CBTp has been assessed by measuring change in positive symptoms (hallucinations and delusions), negative symptoms, quality of life and functioning such that CBTp is now recommended by National Guidelines as rehearsed above (Kuipers et al., 2014). The effectiveness of psychological therapies are not uncontroversial as studies mostly compare CBTp to treatment as usual (Kendall et al., 2016). When compared to an active comparison group, such as befriending, CBTp has less clear evidence. Turkington et al. demonstrate befriending to be particularly useful for persecutory delusions (Turkington 2017). CBTp generally aims to reduce positive symptoms, negative symptoms and improves general functioning (Wykes, Steel, Everitt, \& Tarrier, 2008) and national guidelines currently recommend CBTp for patients with schizophrenia in all phases of the disorder (Kuipers et al., 2014).

With respect to delusional beliefs, only a small number of studies have reported efficacy on delusional beliefs specifically in CBTp trials, or investigated delusional beliefs as the primary outcome, with meta-analysis showing a smaller effect size on delusions compared to hallucinations (van der Gaag, Valmaggia, \& Smit, 2014). Given the prevalence of persecutory as opposed to other delusions, those studies designed to assess the effect of CBTp on delusions mainly focus here. Freeman and et al. examined the effect of CBTp on thirty participants in a single blind RCT and found a significant reduction in paranoia, but also significant improvements in well-being, selfesteem and depression (Freeman et al., 2014). As rehearsed above, given the significance of depression and suicidal thinking in response to delusions and in the generation of positive symptoms, this is not unimportant. 
Although the evidence base for CBTp may be less than perfect, the historical assumption that CBT should not be used in psychosis has been dispelled. In practice, the objectives of psychological therapy are agreed by the patient and therapist in collaboration, and in psychosis may include distressing beliefs, or depression or an entirely different focus. Changing a belief, 'getting rid' of the delusions may well not be the focus of therapy, rather this may include stopping or reducing the time spent thinking about (or acting upon) a belief. However, when focused on delusional beliefs, Turkington proposes that during the cognitive therapy process, expectation is that even primary delusions might become more understandable as the patient's life history and belief profile are made apparent. Techniques involved may include peripheral questioning and inference chaining to explore beliefs once a therapeutic alliance is formed (Turkington \& Siddle, 1998). For example, with Andrew one might discuss an inference question chain such as:

Andrew: "MI5 are training me."

Therapist: "What does it mean for you to believe this?"

Andrew: "There is a reason for everything I've been through."

Therapist: "What does this mean to you to understand this?"

Andrew: "I will be rewarded, money, in the end, for what's been done to me. I don't want to have to do the work, I'd rather have a quiet life, but if I have to this, then maybe at least they will reward me".

There is growing debate about the size of difference can be expected from CBTp; Jauhar found only small differences between CBTp and control groups, which were not significant when only studies that had an active control were pooled (Jauhar et al., 2014). Publication bias and unblinded studies are also highlighted. A more recent meta-analysis of 19 RCT's comparing CBTp and reporting delusions as an outcome found a significant effect with a small to medium effect size that was maintained at 42 weeks when compared to treatment as usual. However in sub-analysis of 8 studies that compared CBTp to another active psychological intervention, there were no significant differences at end of therapy or later follow up (Mehl, Werner, \& Lincoln, 2015). In later studies CBTp was compared to a wide range of interventions supportive counselling (Durham et al., 2003; Lewis et al., 2002; Valmaggia, Van Der Gaag, Tarrier, Pijnenborg, \& Slooff, 2005), attention placebo (O'Connor et al., 2007), psychoeducation (Cather et al., 2005) problem solving (Philippa A 
Garety et al., 2008; Tarrier et al., 2014) and social activity therapy (Haddock, Lowens, Brosnan, Barrowclough, \& Novaco, 2004).

NICE currently recommends CBTp, highlighting the importance of offering this in conjunction with antipsychotic medication, or on its own if medication is declined, as part of a broad-based approach that combines different treatment options tailored to the needs of individual service users (Kuipers et al., 2014). In summary, however it appears psychological therapy may have a beneficial effect in delusional beliefs, and this may be in acting mainly on 'peripheral' but clinically useful targets of distress, depression and acting on beliefs rather than changing the core beliefs system itself.

\subsection{Conclusion}

Psychiatrists are concerned with delusional beliefs because, as all physicians should be, they are interested in human experience and driven by a need to offer therapeutic options to people in need. In general, we become physicians through a combined desire to understand the human condition and to help, be this though biological or other vehicles. The rich descriptions of patient experience in individuals with delusional beliefs are unparalleled in other branches of medicine. Delusional beliefs are at the heart of psychiatry, capturing the essence of this drive to understand and offer real therapeutic opportunity, alleviate suffering, and improve lives. At its best this involves a shared understanding of the context of beliefs, personal meaning and impact. Increasingly we also understand more about the potential biological pathways to delusional thinking, and effectiveness of both pharmacological and psychological interventions. However, the primacy remains of understanding the context in which delusional beliefs are experienced in the round; the role of delusional mood, depression, mania, hallucinations and other positive symptoms, trauma and distress. This has long been recognised to be at the heart of developing a therapeutic relationship, and only when this is established can treatment options be discussed.

\section{REFERENCES}

APA. (2013). DSM 5. American Psychiatric Association.

Arnone, D., McKie, S., Elliott, R., Juhasz, G., Thomas, E., Downey, D., ... Anderson, I. (2013). State-dependent changes in hippocampal grey matter in depression. Molecular Psychiatry, 18(12), 1265-1272. 
Barnes, T. R., \& S. C. G. o. t. B. A. f. P. (2011). Evidence-based guidelines for the pharmacological treatment of schizophrenia: Recommendations from the British Association for Psychopharmacology. Journal of Psychopharmacology, 25(5), 567-620. https://doi.org/10.1177/0269881110391123

Bebbington, P., \& Freeman, D. (2017). Transdiagnostic extension of delusions: Schizophrenia and beyond. Schizophrenia Bulletin, 43(2), 273-282.

Birchwood, M., Gilbert, P., Gilbert, J., Trower, P., Meaden, A., Hay, J., ... Miles, J. N. (2004). Interpersonal and role-related schema influence the relationship with the dominant 'voice'in schizophrenia: A comparison of three models. Psychological Medicine, 34(8), 1571-1580.

Broome, M. R. (2013). The Maudsley reader in phenomenological psychiatry. Cambridge, UK: Cambridge University Press.

Broome, M. R., He, Z., Iftikhar, M., Eyden, J., \& Marwaha, S. (2015). Neurobiological and behavioural studies of affective instability in clinical populations: A systematic review. Neuroscience \& Biobehavioral Reviews, 51, 243-254.

Broome, M. R., Johns, L., Valli, I., Woolley, J., Tabraham, P., Brett, C., ... McGuire, P. (2007). Delusion formation and reasoning biases in those at clinical high risk for psychosis. The British Journal of Psychiatry, 191(51), s38-s42.

Brunet, K., Birchwood, M., Upthegrove, R., Michail, M., \& Ross, K. (2012). A prospective study of PTSD following recovery from first-episode psychosis: The threat from persecutors, voices, and patienthood. British Journal of Clinical Psychology, 51(4), 418-433.

Busatto, G. F. (2013). Structural and functional neuroimaging studies in major depressive disorder with psychotic features: A critical review. Schizophrenia Bulletin, 39(4), 776-786.

Cannon, M., Clarke, M. C., \& Cotter, D. R. (2014). Priming the brain for psychosis: Maternal inflammation during fetal development and the risk of later psychiatric disorder. American Journal of Psychiatry, 171, 91-94.

Cather, C., Penn, D., Otto, M. W., Yovel, I., Mueser, K. T., \& Goff, D. C. (2005). A pilot study of functional Cognitive Behavioral Therapy (fCBT) for schizophrenia. Schizophrenia Research, 74(2), 201-209.

Catone, G., Marwaha, S., Kuipers, E., Lennox, B., Freeman, D., Bebbington, P., \& Broome, M. (2015). Bullying victimisation and risk of psychotic phenomena: Analyses of British national survey data. The Lancet Psychiatry, 2(7), 618-624.

Chisholm, B., Freeman, D., \& Cooke, A. (2006). Identifying potential predictors of traumatic reactions to psychotic episodes. British Journal of Clinical Psychology, 45(4), 545-559.

Clark, D. M. (2011). Implementing NICE guidelines for the psychological treatment of depression and anxiety disorders: The IAPT experience. International Review of Psychiatry, 23(4), 318-327. 
Cornblatt, B. A., Lencz, T., Smith, C. W., Correll, C. U., Auther, A. M., \& Nakayama, E. (2003). The schizophrenia prodrome revisited: A neurodevelopmental perspective. Schizophrenia Bulletin, 29(4), 633-651.

Daalman, K., Diederen, K., Derks, E. M., van Lutterveld, R., Kahn, R. S., \& Sommer, I. E. (2012). Childhood trauma and auditory verbal hallucinations. Psychological Medicine, 42(12), 2475-2484.

Drake, R. J., Haley, C. J., Akhtar, S., \& Lewis, S. W. (2000). Causes and consequences of duration of untreated psychosis in schizophrenia. The British Journal of Psychiatry, 177(6), 511-515.

Durham, R. C., Guthrie, M., Morton, R. V., Reid, D. A., Treliving, L. R., Fowler, D., \& MacDonald, R. R. (2003). Tayside-Fife clinical trial of cognitiveBehavioural therapy for medication-resistant psychotic symptoms. The British Journal of Psychiatry, 182(4), 303-311.

Etain, B., Henry, C., Bellivier, F., Mathieu, F., \& Leboyer, M. (2008). Beyond genetics: Childhood affective trauma in bipolar disorder. Bipolar Disorders, 10(8), 867-876.

Fenton, W. S., McGlashan, T. H., Victor, B. J., \& Blyler, C. R. (1997). Symptoms, subtype, and suicidality in patients with schizophrenia spectrum disorders. The American Journal of Psychiatry, 154(2), 199-204.

Freeman, D., Garety, P. A., \& Kuipers, E. (2001). Persecutory delusions: Developing the understanding of belief maintenance and emotional distress. Psychological Medicine, 31(7), 1293-1306.

Freeman, D., Garety, P. A., Kuipers, E., Fowler, D., Bebbington, P. E., \& Dunn, G. (2007). Acting on persecutory delusions: The importance of safety seeking. Behaviour Research and Therapy, 45(1), 89-99.

Freeman, D., Pugh, K., Dunn, G., Evans, N., Sheaves, B., Waite, F., ... Fowler, D. (2014). An early Phase II randomised controlled trial testing the effect on persecutory delusions of using CBT to reduce negative cognitions about the self: The potential benefits of enhancing self confidence. Schizophrenia Research, 160(1), 186-192.

Garety, P. A., Fowler, D. G., Freeman, D., Bebbington, P., Dunn, G., \& Kuipers, E. (2008). Cognitive-behavioural therapy and family intervention for relapse prevention and symptom reduction in psychosis: Randomised controlled trial. The British Journal of Psychiatry, 192(6), 412-423.

Garety, P. A., \& Freeman, D. (1999). Cognitive approaches to delusions: A critical review of theories and evidence. The British Journal of Clinical Psychology / The British Psychological Society, 38.(Pt 2, 113-154.

Garety, P. A., Kuipers, E., Fowler, D., Freeman, D., \& Bebbington, P. (2001). A cognitive model of the positive symptoms of psychosis. Psychological Medicine, 31(2), 189-195.

Gilbert, P., Birchwood, M., Gilbert, J., Trower, P., Hay, J., Murray, B., ... Miles, J. N. (2001). An exploration of evolved mental mechanisms for dominant and 
subordinate behaviour in relation to auditory hallucinations in schizophrenia and critical thoughts in depression. Psychological Medicine, 31(6), 1117-1127.

Goff, D. C., Falkai, P., Fleischhacker, W. W., Girgis, R. R., Kahn, R. M., Uchida, H., ... Lieberman, J. A. (2017). The long-term effects of antipsychotic medication on clinical course in schizophrenia. American Journal of Psychiatry, 174(9), 840-849.

Gregory, A., Mallikarjun, P., \& Upthegrove, R. (2017). Treatment of depression in schizophrenia: Systematic review and meta-analysis. The British Journal of Psychiatry, 211, 198-204.

Haddock, G., Lowens, I., Brosnan, N., Barrowclough, C., \& Novaco, R. W. (2004). Cognitive-behaviour therapy for inpatients with psychosis and anger problems within a low secure environment. Behavioural and Cognitive Psychotherapy, 32(1), 77-98.

Helfer, B., Samara, M. T., Huhn, M., Klupp, E., Leucht, C., Zhu, Y., ... Leucht, S. (2016). Efficacy and safety of antidepressants added to antipsychotics for schizophrenia: A systematic review and meta-analysis. American Journal of Psychiatry, 173, 876.

Howes, O. D., Kambeitz, J., Kim, E., Stahl, D., Slifstein, M., Abi-Dargham, A., \& Kapur, S. (2012). The nature of dopamine dysfunction in schizophrenia and what this means for treatment: Meta-analysis of imaging studies. Archives of General Psychiatry, 69(8), 776-786.

Huber, G., \& Gross, G. (1989). The concept of basic symptoms in schizophrenic and schizoaffective psychoses. Recenti Progressi in Medicina, 80(12), 646-652.

Jaspers, K. (1997). General psychopathology (Vol. 2). Baltimore, MD: JHU Press.

Jauhar, S., McKenna, P., Radua, J., Fung, E., Salvador, R., \& Laws, K. (2014). Cognitive-behavioural therapy for the symptoms of schizophrenia: Systematic review and meta-analysis with examination of potential bias. The British Journal of Psychiatry, 204(1), 20-29.

Kahn, R. S., Fleischhacker, W. W., Boter, H., Davidson, M., Vergouwe, Y., Keet, I. P., ... Libiger, J. (2008). Effectiveness of antipsychotic drugs in first-episode schizophrenia and schizophreniform disorder: An open randomised clinical trial. The Lancet, 371(9618), 1085-1097.

Kapur, S. (2003). Psychosis as a state of aberrant salience: A framework linking biology, phenomenology, and pharmacology in schizophrenia. American Journal of Psychiatry, 160(1), 13-23.

Kelleher, I., \& Cannon, M. (2011). Psychotic-like experiences in the general population: Characterizing a high-risk group for psychosis. Psychological Medicine, $41,1), 1-1), 6$.

Kendall, T., Whittington, C. J., Kuipers, E., Johnson, S., Birchwood, M. J., Marshall, M., \& Morrison, A. P. (2016). NICE v. SIGN on psychosis and schizophrenia: Same roots, similar guidelines, different interpretations. The British Journal of Psychiatry, 208(4), 316-319. 
Kesting, M.-L., \& Lincoln, T. M. (2013). The relevance of self-esteem and selfschemas to persecutory delusions: A systematic review. Comprehensive Psychiatry, 54(7), 766-789.

Kuipers, E., Yesufu-Udechuku, A., Taylor, C., \& Kendall, T. (2014). Management of psychosis and schizophrenia in adults: Summary of updated NICE guidance. BMJ: British Medical Journal, 348, gl173.

Kumari, V., Peters, E., Guinn, A., Fannon, D., Russell, T., Sumich, A., ... Williams, S. C. (2015). Mapping depression in schizophrenia: A functional magnetic resonance imaging study. Schizophrenia Bulletin, 42, 802-813.

Lally, J., Ajnakina, O., Stubbs, B., Cullinane, M., Murphy, K. C., Gaughran, F., \& Murray, R. M. (2017). Remission and recovery from first-episode psychosis in adults: Systematic review and meta-analysis of long-term outcome studies. The British Journal of Psychiatry: the Journal of Mental Science, 211(6), 350-358.

Lataster, T., Valmaggia, L., Lardinois, M., van Os, J., \& Myin-Germeys, I. (2013). Increased stress reactivity: A mechanism specifically associated with the positive symptoms of psychotic disorder. Psychological Medicine, 43(7), 1389-1400. https://doi.org/10.1017/S0033291712002279

Lee, S.-H., Niznikiewicz, M., Asami, T., Otsuka, T., Salisbury, D. F., Shenton, M. E., \& McCarley, R. W. (2015). Initial and progressive gray matter abnormalities in insular gyrus and temporal pole in first-episode schizophrenia contrasted with first-episode affective psychosis. Schizophrenia Bulletin. https:// doi.org/10.1093/schbul/sbv177

Leucht, S., Tardy, M., Komossa, K., Heres, S., Kissling, W., Salanti, G., \& Davis, J. M. (2012). Antipsychotic drugs versus placebo for relapse prevention in schizophrenia: A systematic review and meta-analysis. The Lancet, 379(9831), 2063-2071.

Lewis, S., Tarrier, N., Haddock, G., Bentall, R., Kinderman, P., Kingdon, D., ... Leadley, K. (2002). Randomised controlled trial of cognitive-Behavioural therapy in early schizophrenia: Acute-phase outcomes. The British Journal of Psychiatry, 181(43), s91-s97.

Maj, M. (2013). Karl jaspers and the genesis of delusions in schizophrenia. Oxford: Oxford University Press US.

Marwaha, S., Thompson, A., Upthegrove, R., \& Broome, M. R. (2016). 15 Years on-Early Intervention for a new generation. Bristish Journal of Psychiatry, 209(3), 186-188.

Mehl, S., Werner, D., \& Lincoln, T. M. (2015). Does Cognitive Behavior Therapy for psychosis show a sustainable effect on delusions? A meta-analysis. Frontiers in Psychology, 6, 1450.

Michail, M., \& Birchwood, M. (2009). Social anxiety disorder in first-episode psychosis: Incidence, phenomenology and relationship with paranoia. The British Journal of Psychiatry, 195(3), 234-241. 
Mishara, A. L., \& Fusar-Poli, P. (2013). The phenomenology and neurobiology of delusion formation during psychosis onset: Jaspers, Truman symptoms, and aberrant salience. Schizophrenia Bulletin, 39(2), 278-286.

Mondelli, V., Cattaneo, A., Murri, M. B., Di Forti, M., Handley, R., Hepgul, N., ... Aitchison, K. J. (2011). Stress and inflammation reduce brain-derived neurotrophic factor expression in first-episode psychosis: A pathway to smaller hippocampal volume. The Journal of Clinical Psychiatry, 72(12), 1478-1684.

Murray, G., Corlett, P., Clark, L., Pessiglione, M., Blackwell, A., Honey, G., ... Fletcher, P. (2008). How dopamine dysregulation leads to psychotic symptoms? Abnormal mesolimbic and mesostriatal prediction error signalling in psychosis. Molecular Psychiatry, 13(3), 239.

Murray, R. M., Quattrone, D., Natesan, S., van Os, J., Nordentoft, M., Howes, O., ... Taylor, D. (2016). Should psychiatrists be more cautious about the long-term prophylactic use of antipsychotics? The British Journal of Psychiatry, 209(5), 361-365.

Nelson, B., Yuen, H. P., Wood, S. J., Lin, A., Spiliotacopoulos, D., Bruxner, A., ... Yung, A. R. (2013). Long-term follow-up of a group at ultra high risk ("prodromal") for psychosis: The PACE 400 study. JAMA Psychiatry, 70(8), 793-802. https://doi.org/10.1001/jamapsychiatry.2013.1270

Neria, Y., Nandi, A., \& Galea, S. (2008). Post-traumatic stress disorder following disasters: A systematic review. Psychological Medicine, 38(4), 467-480.

Noto, C., Ota, V. K., Santoro, M. L., Ortiz, B. B., Rizzo, L. B., Higuchi, C. H., ... Gadelha, A. (2015). Effects of depression on the cytokine profile in drug naive first-episode psychosis. Schizophrenia Research, 164(1), 53-58.

O’Connor, K., Stip, E., Pélissier, M.-C., Aardema, F., Guay, S., Gaudette, G., ... Careau, Y. (2007). Treating delusional disorder: A comparison of cognitivebehavioural therapy and attention placebo control. The Canadian Journal of Psychiatry, 52(3), 182-190.

Oyebode, F. (2014). Sims' symptoms in the mind: Textbook of descriptive psychopathology. Philadelphia: Elsevier Health Sciences.

Palaniyappan, L., Mallikarjun, P., Joseph, V., White, T., \& Liddle, P. (2011). Reality distortion is related to the structure of the salience network in schizophrenia. Psychological Medicine, 41(8), 1701-1708.

Perälä, J., Suvisaari, J., Saarni, S. I., Kuoppasalmi, K., Isometsä, E., Pirkola, S., ... Kieseppä, T. (2007). Lifetime prevalence of psychotic and bipolar I disorders in a general population. Archives of General Psychiatry, 64(1), 19-28.

Pierre, J. M. (2010). Hallucinations in nonpsychotic disorders: Toward a differential diagnosis of "hearing voices". Harvard Review of Psychiatry, 18(1), 22-35.

Reniers, R. L., Lin, A., Yung, A. R., Koutsouleris, N., Nelson, B., Cropley, V. L., ... Wood, S. J. (2017). Neuroanatomical predictors of functional outcome in individuals at ultra-high risk for psychosis. Schizophrenia Bulletin, 43(2), 449-458. 
Rüsch, N., Angermeyer, M. C., \& Corrigan, P. W. (2005). Mental illness stigma: Concepts, consequences, and initiatives to reduce stigma. European Psychiatry, 20(8), 529-539. https://doi.org/10.1016/j.eurpsy.2005.04.004

Sandhu, A., Ives, J., Birchwood, M., \& Upthegrove, R. (2013). The subjective experience and phenomenology of depression following first episode psychosis: A qualitative study using photo-elicitation. Journal of Affective Disorders, 149 (1), 166-174.

Schultze-Lutter, F., Klosterkötter, J., \& Ruhrmann, S. (2014). Improving the clinical prediction of psychosis by combining ultra-high risk criteria and cognitive basic symptoms. Schizophrenia Research, 154(1), 100-106.

Schultze-Lutter, F., Ruhrmann, S., Berning, J., Maier, W., \& Klosterkötter, J. (2008). Basic symptoms and ultrahigh risk criteria: Symptom development in the initial prodromal state. Schizophrenia Bulletin, 36(1), 182-191.

Smieskova, R., Fusar-Poli, P., Allen, P., Bendfeldt, K., Stieglitz, R., Drewe, J., ... Borgwardt, S. (2010). Neuroimaging predictors of transition to psychosis-A systematic review and meta-analysis. Neuroscience \& Biobehavioral Reviews, 34(8), 1207-1222.

Stanghellini, G., \& Fuchs, T. (2013). One century of Karl Jaspers' general psychopathology. Oxford: Oxford University Press.

Staring, A., Van der Gaag, M., Van den Berge, M., Duivenvoorden, H., \& Mulder, C. (2009). Stigma moderates the associations of insight with depressed mood, low self-esteem, and low quality of life in patients with schizophrenia spectrum disorders. Schizophrenia Research, 115(2), 363-369.

Tarrier, N., Kelly, J., Maqsood, S., Snelson, N., Maxwell, J., Law, H., ... Gooding, P. (2014). The cognitive behavioural prevention of suicide in psychosis: A clinical trial. Schizophrenia Research, 156(2), 204-210.

Taylor, M., \& Perera, U. (2015). NICE CG178 Psychosis and Schizophrenia in Adults: Treatment and Management-an evidence-based guideline? RCP.

Tiihonen, J., Mittendorfer-Rutz, E., Majak, M., Mehtälä, J., Hoti, F., Jedenius, E., ... Tanskanen, A. (2017). Real-world effectiveness of antipsychotic treatments in a nationwide cohort of 29823 patients with schizophrenia. JAMA Psychiatry, 74(7), 686-693.

Turkington, D., \& Siddle, R. (1998). Cognitive therapy for the treatment of delusions. Advances in Psychiatric Treatment, 4(4), 235-24l.

Upthegrove, R., Birchwood, M., Ross, K., Brunett, K., McCollum, R., \& Jones, L. (2010). The evolution of depression and suicidality in first episode psychosis. Acta Psychiatrica Scandinavica, 122(3), 211-218. https://doi.org/10.1111/ j.1600-0447.2009.01506.x

Upthegrove, R., Broome, M., Caldwell, K., Ives, J., Oyebode, F., \& Wood, S. (2015). Understanding auditory verbal hallucinations: A systematic review of current evidence. Acta Psychiatrica Scandinavica, 133, 352-367. 
Upthegrove, R., Chard, C., Jones, L., Gordon-Smith, K., Forty, L., Jones, I., \& Craddock, N. (2015). Adverse childhood events and psychosis in bipolar affective disorder. The British Journal of Psychiatry, 206(3), 191-197.

Upthegrove, R., Ives, J., Broome, M. R., Caldwell, K., Wood, S. J., \& Oyebode, F. (2016). Auditory verbal hallucinations in first-episode psychosis: A phenomenological investigation. British Journal of Psychiatry Open, 2(1), 88-95.

Upthegrove, R., Manzanares-Teson, N., \& Barnes, N. M. (2014). Cytokine function in medication-naive first episode psychosis: A systematic review and metaanalysis. Schizophrenia Research, 155(1), 101-108.

Upthegrove, R., Marwaha, S., \& Birchwood, M. (2016). Depression and schizophrenia: Cause, consequence or trans-diagnostic issue? Schizophrenia Bulletin, sbw097.

Upthegrove, R., Ross, K., Brunet, K., McCollum, R., \& Jones, L. (2014). Depression in first episode psychosis: The role of subordination and shame. Psychiatry Research, 217(3), 177-184.

Valmaggia, L. R., Van Der Gaag, M., Tarrier, N., Pijnenborg, M., \& Slooff, C. J. (2005). Cognitive-behavioural therapy for refractory psychotic symptoms of schizophrenia resistant to atypical antipsychotic medication. The British Journal of Psychiatry, 186(4), 324-330.

van der Gaag, M., Valmaggia, L. R., \& Smit, F. (2014). The effects of individually tailored formulation-based cognitive behavioural therapy in auditory hallucinations and delusions: A meta-analysis. Schizophrenia Research, 156(1), 30-37.

Vermeulen, J., van Rooijen, G., Doedens, P., Numminen, E., van Tricht, M., \& de Haan, L. (2017). Antipsychotic medication and long-term mortality risk in patients with schizophrenia; a systematic review and meta-analysis. Psychological Medicine, 47(13), 2217-2228.

Wykes, T., Steel, C., Everitt, B., \& Tarrier, N. (2008). Cognitive behavior therapy for schizophrenia: Effect sizes, clinical models, and methodological rigor. Schizophrenia Bulletin, 34(3), 523-537.

Yung, A. R., Nelson, B., Stanford, C., Simmons, M. B., Cosgrave, E. M., Killackey, E., ... McGorry, P. D. (2008). Validation of "prodromal" criteria to detect individuals at ultra high risk of psychosis: 2 year follow-up. Schizophrenia Research, 105(1-3), 10-17.

Yung, A. R., Pan Yuen, H., Mcgorry, P. D., Phillips, L. J., Kelly, D., Dell'olio, M., ... Buckby, J. (2005). Mapping the onset of psychosis: The comprehensive assessment of at-risk mental states. Australian and New Zealand Journal of Psychiatry, 39(11-12), 964-971. https://doi.org/10.1080/j.1440-1614.2005.01714.x 
Open Access This chapter is licensed under the terms of the Creative Commons Attribution 4.0 International License (http://creativecommons.org/licenses/ by $/ 4.0 /$ ), which permits use, sharing, adaptation, distribution and reproduction in any medium or format, as long as you give appropriate credit to the original author(s) and the source, provide a link to the Creative Commons license and indicate if changes were made.

The images or other third party material in this chapter are included in the chapter's Creative Commons license, unless indicated otherwise in a credit line to the material. If material is not included in the chapter's Creative Commons license and your intended use is not permitted by statutory regulation or exceeds the permitted use, you will need to obtain permission directly from the copyright holder.

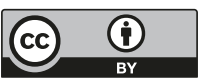

